\title{
Comparison of quality-of-life instruments for assessing the participation after stroke based on the International Classification of Functioning, Disability and Health (ICF)
}

\author{
Soraia M. Silva ${ }^{1}$, Fernanda I. Corrêa ${ }^{1}$, Christina D. C. M. Faria ${ }^{2}$, \\ João C. F. Corrêa ${ }^{1}$
}

\begin{abstract}
Background: According to the International Classification of Functioning, Disability and Health (ICF), the participation component is considered to be the most complex component characterized in existing instruments that assess quality of life related to health (HRQoL). Questionnaires such as the Nottingham Health Profile (NHP) and the Stroke-Specific Quality of Life (SS-QOL) are currently used to evaluate the participation of individuals in life activities after stroke. However, because participation and HRQoL are different constructs, it is unclear whether these instruments are best suited to this evaluation. Objective: To investigate whether the NHP and SS-QOL are suitable instruments for assessing the participation component of ICF. Method: A cross-sectional study was conducted in which a sample of 35 individuals completed the SS-QOL and NHP. The study correlated the total score on the questionnaires with the scores on items that evaluate the participation component of the ICF. Both analyses used the Spearman correlation coefficient (r). Results: There was a statistically significant, positive and strong correlation between total score on the SS-QOL and NHP and the score on specific components related to participation $(\mathrm{r}=0.8, \mathrm{p}=0.001$ and $\mathrm{r}=0.9, \mathrm{p}=0.001$, respectively). Conclusions: Both the NHP and the SS-QOL show strong correlations between the total score and the score on items that assess the participation categories of the ICF. However, the SS-QOL questionnaire appeared to be the most complete for this assessment because it evaluates more distinct domains and contains the largest number of items related to participation.
\end{abstract}

Keywords: stroke; quality of life; International Classification of Functioning, disability and health; physical therapy.

\section{HOW TO CITE THIS ARTICLE}

Silva SM, Corrêa FI, Faria CDCM, Corrêa JCF. Comparison of quality-of-life instruments for assessing the participation after stroke based on the International Classification of Functioning, Disability and Health (ICF). Braz J Phys Ther. 2013 Sept-Oct; 17(5):470-478. http://dx.doi.org/10.1590/S1413-35552012005000118

\section{Introduction}

Stroke ${ }^{1,2}$ has a high incidence and prevalence among the world population. Of the estimated 62 million stroke survivors worldwide ${ }^{3}$, approximately $90 \%$ develop some sort of disability ${ }^{4}$. In a study of the prevalence of diseases conducted in conjunction with the World Health Organization (WHO), stroke was designated the third leading cause of disabilityadjusted life years (DALY) in developed countries and the sixth leading cause worldwide ${ }^{5}$.

Stroke was one of the first diseases to receive attention from research groups studying functionality based on the framework of the International Classification of Functioning, Disability and Health
$(\mathrm{ICF})^{6,7}$. The theoretical model described by the ICF is based on the use of a biopsychosocial approach that integrates biological, individual and social determinants of health. According to the ICF model, functionality is a comprehensive term that includes the interaction of the positive aspects among its three components: body structure and function, activity and participation. All of these levels of functionality can be influenced by personal and environmental factors, which can act as facilitators or barriers to performing activities and to participation ${ }^{8}$.

Based on the conceptual framework of the ICF, the participation component was identified as the most

${ }^{1}$ Graduate Program in Rehabilitation Sciences, Universidade Nove de Julho (UNINOVE), São Paulo, SP, Brazil 
complex component that is evaluated by existing instruments ${ }^{9,10}$. This is in part due to the fact that the components "activity" and "participation" share a single coding list ${ }^{8}$. Thus, the use of instruments previously developed to measure health-related quality of life (HRQoL) constructs have been suggested for use in assessing participation following a stroke ${ }^{6,11}$. According to Geyh et al. ${ }^{12}$, both HRQoL and participation are constructs that are geared toward the patient, favoring the interposable use of these concepts. This may be one of the reasons that HRQoL instruments were initially indicated as most suitable for evaluating the participation component.

However, participation and HRQoL are distinct constructs; whereas the former refers to an individual's involvement in a real-life situation ${ }^{8}$, the latter is related to the restrictions associated with a specific health condition ${ }^{12,13}$. The term 'HRQoL' refers to an individual's perception regarding his/her illness and its effects on his/her life, including personal satisfaction associated with that individual's physical, functional, emotional and social well-being ${ }^{14}$. In contrast, the participation construct is related to the synthesis of the capabilities and accomplishment of the subject in his/her everyday environment, and this synthesis is viewed within a social context that considers both environmental and personal factors as facilitators or barriers ${ }^{8}$.

Based on the functionality model of the ICF, Salter et al. ${ }^{11}$ and Barak and Duncan ${ }^{6}$ indicated that the Nottingham Health Profile (NHP) and the StrokeSpecific Quality of Life (SS-QOL) measurement instruments were the most suitable for assessing participation following a stroke. However, more recent studies have noted that the concepts on which some items in these instruments are based are not related to the participation component ${ }^{12,15,16}$. Furthermore, although separate assessment of "activity" and "participation" components has been recommended in the literature ${ }^{6,11}$, these components are not differentiated and are therefore listed on a single coding list ${ }^{8}$. Therefore, the categories evaluated in the above-described instruments assess both "activity" and "participation". Thus, contrary to what was previously thought, HRQoL instruments may not be the most suitable instruments for assessing the participation component.

Given the above, it is necessary to evaluate the potential and the limitations of these instruments in assessing participation. The aim of this study was to determine whether the NHP and the SS-QOL are appropriate for evaluating the participation component of the ICF. This study also aims to give scientific credibility to the process of evaluating individuals with hemiparesis by providing relevant data for developing appropriate treatment plans to improve the social participation of this population.

\section{Method}

\section{Study design}

This study is a cross-sectional observational study in which participants with chronic hemiparesis due to stroke were recruited from the Department of Physical Therapy, Universidade Nove de Julho (UNINOVE), São Paulo, SP, Brazil. The following inclusion criteria were established: clinical diagnosis of a primary or recurrent stroke that occurred more than six months previously, 20 years of age or older, of either gender and presenting with hemiparesis due to stroke. Individuals were excluded from the study if they had another medical condition associated with stroke and if they had motor aphasia or comprehension deficits or presented with cognitive impairment as assessed via the Mini-Mental State Examination (MMSE), considering the cutoff points described by Bertolucci et al. ${ }^{17}$.

\section{Ethical aspects}

This study followed the tenets of the Declaration of Helsinki and the Guidelines and Regulatory Standards for research involving humans formulated by the National Health Council, Ministry of Health established in October 1996 in Brazil.

All participants signed an informed consent form and were notified that they were permitted to withdraw from the study at any time without penalty. This study was reviewed and approved by the UNINOVE Committee for Ethics in Research (Protocol No. 362861/10).

\section{Assessment instruments}

\section{Nottingham Health Profile (NHP)}

Of the generic instruments available for assessing a patient's quality of life following a stroke (NHP and SF-36), the Nottingham Health Profile (NHP) version adapted for Brazilian Portuguese [translated as Perfil de Saúde de Nottingham (PSN) ${ }^{18}$ ] was selected for this study because the 38 items on the questionnaire 
are based on the ICF. In addition, this instrument provides a simple measure of the physical, social and emotional well-being of the individual. The reliability of the NHP for individuals affected by a stroke was evaluated by Cabral et al. ${ }^{19}$, who concluded that the instrument had adequate measurement properties and could therefore be used for this population. The questions included in the instrument had a yes/ no format and were grouped into the following areas: physical ability, energy level, pain, emotional reactions, sleep quality and social isolation. A score of (1) was given for each "no" answer (positive perception of HRQoL), and a score of (0) was given for each "yes" answer (negative perception of HRQoL), for a maximum score of 38 points. A percentage of $(0)$ to $(100)$ was calculated from the sum of the "no" answers; percentages closer to $100 \%$ indicated a better perception of HRQoL, and lower percentages indicated a worse perception of HRQoL.

The selection of specific items from the participation component from the ICF was based on the agreement of two independent examiners who had adequate knowledge of the conceptual framework and taxonomy theory on which the ICF is based. These examiners are associated with the ICF research Branch. The examiners followed the linking rules between each item on the instrument and the ICF categories described by Stucki et al. ${ }^{20}$ In this way, the examiners identified which ICF categories were assessed by items that comprise the NHP. In the absence of a consensus, a third reviewer was consulted.

The scoring of items from the ICF was performed in a similar manner as the scoring of other questions on the instrument. Thus, a score of (1) was given for each "no" answer, and a score of (0) was given for each "yes" answer, for a total maximum score of 13 points. Scores closer to the maximum score indicated better participation by the individual.

\section{Stroke-Specific Quality of Life (SS-QOL)}

The adaptation of the Brazilian version of Stroke-Specific Quality of Life (SS-QOL), translated as Escala de Qualidade de Vida Específica para Acidente Vascular Encefálico (EQVE-AVE), was used as a specific measure of the quality of life ${ }^{21}$. The measurement properties of the Brazilian version of the SS-QOL were assessed by Lima et al. ${ }^{21}$, who concluded that the instrument was adequate and clinically useful for the population evaluated.
The SS-QOL includes twelve areas (energy, family role, language, mobility, mood, personality, self-care, social roles, thinking, upper-extremity function, vision and work/productivity) that are covered by 49 items. For each item, there are five response options in which the score for each item may vary from 1 to 5 . Thus, the minimum overall score for the questionnaire is 49 (worst perception of quality of life) and the maximum score is 245 (best perception of quality of life).

The identification of items on the questionnaire that are specific to the activity and participation components of the ICF was based on a study by Teixeira-Salmela et al. ${ }^{16}$ in which two evaluators completed the linking between the SS-QOL items and the ICF categories. In the absence of a consensus, a third reviewer was consulted. The scoring of items specific for the activity and participation components of the ICF used the same scoring system as was used in the SS-QOL. Thus, the minimum obtainable score was 26 points, and the maximum obtainable score was 130 points; higher scores indicated better participation by the individual.

\section{Procedures for data collection}

After all the volunteers had been invited to participate in the study, an individual interview and a physical examination of each participant were conducted to ensure that the inclusion and exclusion criteria of the study were met; only then did the volunteers undergo the evaluation.

Although the instruments are self-administered, they were provided to the volunteers by a single examiner who had been trained using a theoretical and practical approach to the assessment instruments. During the interview, the volunteers completed a questionnaire in which demographic and clinical variables were used to characterize gender, age, time following stroke, type of stroke, number of stroke episodes, hemisphere affected and hospitalization time of the sample population. Subsequently, each individual answered the SS-QOL and NHP questions. The instruments were administered randomly based on a draw from a sealed opaque envelope performed by the volunteer.

Depending on the socio-cultural characteristics of the sample population, the participants could opt to have the questionnaires administered in the form of an interview. When the interview format was used, the questions were read in the same order as they appeared in the printed questionnaire, as 
previously recommended by a study of the Brazilian population $^{18}$.

\section{Statistical analysis}

To determine the number of individuals to be evaluated, a sample calculation was performed using the correlation results of the total score between the SS-QOL and NHP instruments obtained in a pilot study that consisted of the first ten subjects evaluated, considering $\alpha=0.05$ and $\beta=0.2$ ( $80 \%$ power) and assuming $r=0.70$, which is higher than the $\mathrm{r}$ value resulting from the pilot study (0.69). Based on the pilot study, an $n$ value of 15 subjects was calculated to be necessary; this number was increased by $30 \%$ to account for possible losses during the study, for a final $n$ value of at least 19 individuals.

For sample characterization and assessment of the distribution of scores, descriptive statistics were used, including measures of central tendency (mean) and dispersion (standard deviation) for quantitative variables and frequency for categorical variables. Nonparametric variables were summarized as median and interquartile range values.

When the data were analyzed using the ShapiroWilk normality test, it was noted that the analyzed variables were non-parametric. Thus, the degree of association between the two instruments was analyzed using the Spearman correlation coefficient $(r)$. To this end, the total score on the instruments and the score on items specific to the activity and participation components of the ICF were considered.

The force or magnitude of the relationship between variables was classified as poor (correlation coefficient between 0.1 and 0.3 ), moderate (correlation coefficient between 0.4 and 0.6 ) or strong (correlation coefficient between 0.7 and 0.9$)^{22}$. In all the inferential analyses, a significance level of $\alpha=0.05$ was used.

\section{Results}

In total, 56 subjects with chronic hemiparesis were recruited; of these, nine were excluded for presenting with aphasia, eight for having a positive cutoff for cognitive impairment screening and four for presenting with other diseases associated with stroke. Thus, the final sample consisted of 35 individuals who were evaluated in the outpatient physical therapy clinics at Nove de Julho University. The demographic and clinical characteristics of these individuals are presented in Table 1.
Table 2 shows the items in the SS-QOL that were identified as related to the activity and participation components of the ICF. Of the 49 items in this instrument, only 26 assess the activity and participation components. Of the 12 areas assessed by the SS-QOL questionnaire, four ("energy", "mood", "personality" and "vision") do not assess activity and participation.

Table 3 indicates that of the 38 items on the NHP questionnaire, 13 assess the activity and participation components; of the six domains on this questionnaire that include HRQoL assessment, three ("physical skills", "social interaction" and "pain") are associated with the activity and participation components.

When used to evaluate the quality of life of the sample population recruited for this study, the SSQOL and NHP instruments showed a median and interquartile ranges (25\% and $75 \%$ ) of $179(163 / 199)$ and 26 (17/33), respectively, for the total scores. The correlation between the total scores on the two instruments was statistically significant, positive and strong $(r=0.7, p<0.001)$. However, the correlation between the scores on specific items of the activity and participation components on the two instruments was moderate $(r=0.5, p=0.01)$.

The correlation between the total SS-QOL score and the scores on specific items that address the activity and participation components was statistically significant, positive and strong (Figure 1). For the NHP, the correlation between the total score and specific scores for the activity and participation components was also statistically significant, positive and strong (Figure 2).

\section{Discussion}

This study compared HRQoL and participation assessments by analyzing the correlation between participants' total scores on the instruments and

Table 1. Demographic characteristics of the study volunteers.

\begin{tabular}{lc}
\hline \multicolumn{1}{c}{ Variable } & $(\mathbf{n = 3 5})$ \\
Men & $19(54 \%)$ \\
Women & $16(46 \%)$ \\
Age (years) & $57.3 \pm 13.9$ \\
Time since stroke (years) & $4.1 \pm 3.5$ \\
Right hemisphere affected & $13(37 \%)$ \\
Left hemisphere affected & $22(63 \%)$ \\
\hline
\end{tabular}

Data are expressed as frequency, mean and standard deviation (SD). 
Table 2. Identification of categories of the activity and participation components on the SS-QOL instrument.

\section{SS-QOL item}

\section{Family Roles}

I didn't join in activities just for fun with my family

\section{LANGUAGE}

Did you have trouble speaking?

Did you have trouble speaking clearly enough to use the telephone?

Did you have to repeat yourself so others could understand you?

\section{Mobility}

Did you have trouble walking?

Did you lose your balance when bending over to or reaching for something?

Did you have trouble climbing stairs?

Did you have trouble with standing?

Did you have trouble getting out of a chair?

\section{Self-Care}

Did you need help preparing food?

Did you need help eating?

Did you need help getting dressed?

Did you need help taking a bath or a shower?

Did you need help to use the toilet?

\section{Social Roles}

I did my hobbies and recreation for shorter periods of time than I would like.

I didn't see as many of my friends as I would like.

I had sex less often than I would like.

\section{Thinking}

It was hard for me to concentrate.

\section{Upper Extremity Function}

Did you have trouble writing or typing?

Did you have trouble putting on socks?

Did you have trouble buttoning buttons?

Did you have trouble zipping a zipper?

Did you have trouble opening a jar?

\section{Work/Productivity}

Did you have trouble doing daily work around the house?

Did you have trouble finishing jobs that you started?

Did you have trouble doing the work you used to do?

\section{ICF category}

d920 Recreation and leisure

\author{
d330 Speaking \\ d3600 Using communication devices \\ d350 Conversation
}

\author{
d450 Walking \\ d4105 Bending \\ d4551 Climbing \\ d4154 Maintaining a standing position \\ d4104 Standing
}

d6300 Preparing simple meals

d550 Eating

d540 Dressing

d5101 Washing whole body

d530 Toileting

\section{d7500 Informal relationships with friends d7702 Sexual relationships}

d160 Focusing attention

d440 Fine hand use

d445 Hand and arm use

d440 Fine hand use

d440 Fine hand use

d4453 Turning or twisting the hands or arms

d640 Doing housework

d2201 Completing multiple tasks

d850 Remunerative employment

SS-QOL: Stroke-Specific Quality of Life; ICF: International Classification of Functioning, Disability and Health; d: activities and participation.

their scores on items that assess the participation categories of the ICF. There was strong correlation between the HRQoL assessment and assessment of the participation component of the ICF for both the
SS-QOL and the NHP. In addition, these instruments appear to measure HRQoL similarly. However, the same degree of similarity was not observed for the assessment of participation by the two instruments. 
Table 3. Identification of categories of the activity and participation components on the NHP instrument.

\section{NHP item}

ICF category

\section{Physical Abilities}

I can only walk about indoors.

I find it hard to bend.

I'm unable to walk at all.

I have trouble getting up and down stairs and steps.

I find it hard to reach for things.

I find it hard to dress myself.

I find it hard to stand for long.

I need help to walk about outside.

\section{Social Interaction}

I'm finding it hard to make contact with people.

I'm finding it hard to get on with people.

\section{Pain}

I'm in pain when I'm standing.

I'm in pain when going up and down stairs and steps.

I'm in pain when sitting. d460 Moving around in different locations

d4105 Bending

d450 Walking

d4551 Climbing

d4452 Reaching

d540 Dressing

d4154 Maintaining a standing position

d450 Walking

d710 Basic interpersonal interactions

d710 Basic interpersonal interactions

d4154 Maintaining a standing position

d4551 Climbing

d4153 Maintaining a sitting position

NHP: Nottingham Health Profile; CIF: ICF: International Classification of Functioning, Disability and Health; d: activities and participation.

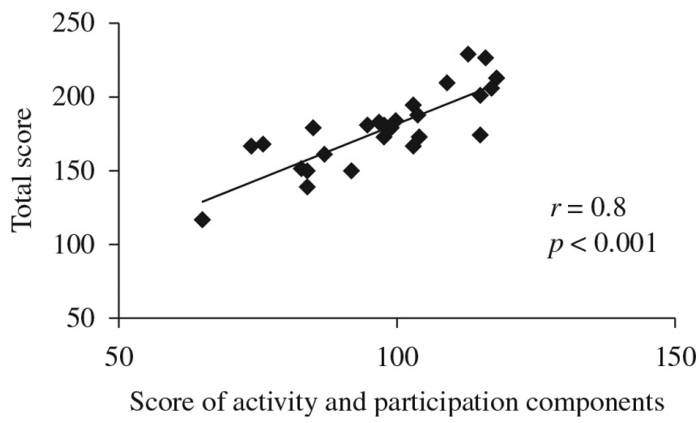

Figure 1. Correlation between total score on the SS-QOL and score on the SS-QOL items that assess activity and participation components.

With respect to the clinical characteristics of the sample population evaluated, the study population presented a predominance of neurological sequelae in the left hemisphere. According to Benvegnu et al. ${ }^{23}$, different clinical manifestations following a stroke are reflections of the affected hemisphere and the extent of the brain injury. Some reports ${ }^{24}$ indicate that patients with left hemisphere involvement exhibit less impairment of the ability to walk and to perform daily activities than patients with sequelae attributed to the right hemisphere. Thus, the differentiation between functional deficits of patients with left- and right-hemisphere neurological sequelae is important

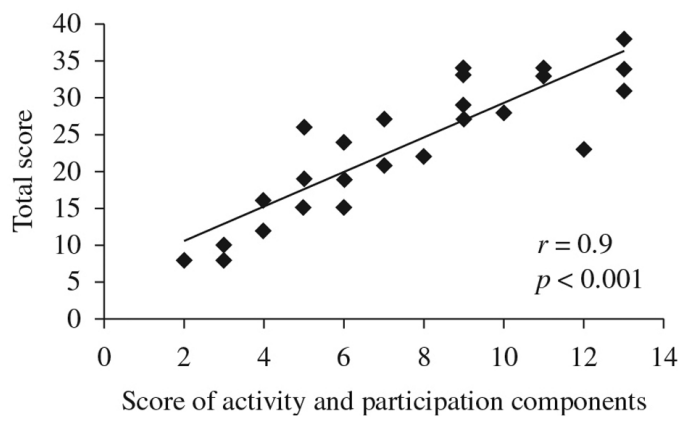

Figure 2. Correlation between total score on the NHP and score on NHP items that assess activity and participation components.

because it can assist in the therapeutic decision process of selecting appropriate activities for each individual $^{24}$.

Based on the results obtained here, there was a positive overall trend among the individuals evaluated regarding their perceived health. This finding may be related to the fact that the sample population consisted of individuals in the chronic phase of stroke; during this period, the recovery of physical and cognitive functions tends to stabilize ${ }^{18}$. Moreover, with time following a stroke, many individuals learn to cope with their limitations, and this process seems to have a positive effect on their HRQoL ${ }^{25}$. 
In analyzing the items on the questionnaires, it was noted that of the 49 items on the SS-QOL, 26 (representing 53\% of the questions on the instrument) evaluate the activity and participation components and that of the 12 areas assessed by the questionnaire, only four ("energy", "mood", "personality" and "vision") do not assess activity and participation. Thus, the following areas of the SS-QOL are associated with activity and participation: "family role", "language", "mobility", "self-care", "social role", "thinking", "upper-extremity function" and "work/productivity".

For the NHP, it was noted that of the 38 items on the questionnaire 13 assess the activity and participation components and that only three of the six domains on the instrument are associated with the activity and participation components; these are "physical abilities", "social interaction" and "pain". Of these, only the last is not measured by the SS-QOL.

Given the above data, it can be inferred that the SS-QOL evaluates more categories of activity and participation than the NHP and that these categories are included in a larger number of domains assessed by the SS-QOL. This finding is consistent with results reported by Faria et al. ${ }^{26}$, who observed that the SS-QOL included more distinct categories related to the participation component than did the NHP. Furthermore, two studies of the NHP ${ }^{27,28}$ found that most of the concepts measured by this instrument are associated with the body function component and not the participation component. Considering these criteria, if the objective is to evaluate participation based on the use of these instruments and if there is a need to select only one of them, the SS-QOL appears to be more indicated. However, if the objective is to assess the impact of pain on the participation of hemiparesis patients, the combined use of both instruments is indicated.

A strong correlation was found between the total scores on the two instruments, demonstrating that these instruments appear to assess quality of life similarly. However, there was only a moderate correlation between the two instruments with respect to scores on items that are directly related to the evaluation of participation. This outcome suggests that these instruments do not measure similar constructs related to participation. This finding may be related to the fact that the SS-QOL has eight domains that include participation, whereas the NHP has only three.
Upon analyzing the correlation between the total scores for the SS-QOL and NHP and the score on items associated with the categories of the participation component of the ICF, there was a statistically significant, positive and strong correlation between score on the SS-QOL $(r=0.8$, $p<0.001)$ and score on the NHP $(r=0.9, p<0.001)$. This indicates that as the HRQoL increases social participation will also increase. Therefore, qualityof-life questionnaires can indeed be used to assess participation following a stroke given the strong correlation between the assessment scores. This finding is consistent with reports by Salter et al. ${ }^{11}$ and Barak and Duncan ${ }^{6}$, which also indicate that quality-of-life instruments are best suited to assess participation following a stroke.

It should be noted that the implementation of some activities identified in the quality-of-life instruments SS-QOL and NHP may not be sufficient to explain the actual involvement of the individual in his/her appropriate context given that they represent an assessment of "activity" and not "participation". This is one of the limitations of using these instruments for this purpose.

One of the primary limitations of this study is that it compares only two HRQoL instruments. Although the SS-QOL and NHP are commonly used with individuals with hemiparesis following a stroke, the SF-36 is another commonly used HRQoL questionnaire that has been suggested in the literature to be suitable for assessing the participation of this population. We chose to use the NHP as a generic instrument because 38 items on the questionnaire were developed based on the ICF.

Despite the limitation noted above, the results presented here are extremely relevant to the field of physical therapy and rehabilitation. First, they provide a better understanding of the participation component of the ICF. Second, they show that the instruments analyzed here are, in fact, appropriate for assessing the participation of patients suffering from hemiparesis due to stroke. Finally, these results contribute to the development of strategies for effective evaluation of stroke patients and provide data that are relevant to the development of appropriate treatment plans for this population. When participation is effectively evaluated, the rehabilitation process can be directed toward more specific objectives that are focused on the individual's expectations, thus contributing to a greater humanization and effectiveness of stroke 
treatment and improving our perception of patients' participation.

In summary, while the results of the present study indicate that both the NHP and the SS-QOL show strong correlations between total scores and scores on items that assess the participation categories of the ICF, the SS-QOL appears to be the most complete instrument for assessing participation because, in addition to evaluating the largest number of participation categories, it also evaluates a larger number of areas that include participation than the NHP.

\section{- Acknowledgements}

The financial support of the Coordination for the Improvement of Higher Education Personnel [Coordenação de Aperfeiçoamento de Pessoal de Nível Superior (CAPES), Brazil,] in conducting this research is gratefully acknowledged.

We also thank researchers of the ICF research Branch, who kindly provided the data for the linking of the NHP to the participation categories of the ICF.

\section{References}

1. MacKay J, Mensah GA. The Atlas of Heart Disease and Stroke. Geneva: World Health Organization; 2002.

2. Chong JY, Sacco RL. Epidemiology of stroke in young adults: race/ethnic differences. J Thromb Thrombolysis. 2005;20:77-83. PMid:16205856. http://dx.doi. org/10.1007/s11239-005-3201-9

3. World Health Organization - WHO. The World Health Report 2000. Health Systems: Improving Performance. Geneva: World Health Organization; 2000.

4. World Health Organization - WHO. Global Burden of DiseasedDeaths, Years of Life Lost and Years Lost Due to Disability. Geneva: World Health Organization; 2011 [cited 2011 Mar 25]. Available from: http://appswhoint/ ghodata/?vid1/472063.

5. Murray CJL, Lopez AD. Global mortality, disability, and the contribution of risk factors: Global burden of disease study. Lancet. 1997;349:1436-42. http://dx.doi. org/10.1016/S0140-6736(96)07495-8

6. Barak S, Duncan PW. Issues in selecting outcome measures to assess functional recovery after stroke. NeuroRX. 2006;3:505-24. PMid:17012065 PMCid:PMC3593403. http://dx.doi.org/10.1016/j.nurx.2006.07.009

7. Tempest S, McIntyre A. Using the ICF to clarify team roles and demonstrate clinical reasoning in stroke rehabilitation. Disabil Rehabil. 2006;28:663-7. PMid:16690581. http:// dx.doi.org/10.1080/09638280500276992

8. Organização Mundial de Saúde - OMS. Classificação Internacional de Funcionalidade, Incapacidade e Saúde. São Paulo: EdUSP; 2003.
9. Jette AM, Haley SM, Kooyoomjian JT. Are the ICF Activity and Participation dimensions distinct? J Rehabil Med. 2003;35:145-9. PMid:12809198. http://dx.doi. org/10.1080/16501970310010501

10. Perenboom RJM, Chorus AMJ. Measuring participation according to the International Classification of Functioning, Disability and Health (ICF). Disabil Rehabil. 2003;25:577-87. PMid:12959331. http://dx.doi. org/10.1080/0963828031000137081

11. Salter K, Jutai JW, Teasell R, Foley NC, Bitensky J, Bayley M. Issues for selection of outcome measures in stroke rehabilitation: ICF Participation. Disabil Rehabil. 2005;27:507-28. PMid:16040555. http://dx.doi. org/10.1080/0963828040008552

12. Geyh S, Cieza A, Kollerits B, Grimby G, Stucki G. Content comparison of health-related quality of life measures used in stroke based on the international classification of functioning, disability and health (ICF): a systematic review. Qual Life Res. 2007;16:833-51. PMid:17294283. http://dx.doi.org/10.1007/s11136-007-9174-8

13. Cieza A, Stucki G. The International Classification of Functioning, Disability and Health: Its development process and content validity. Eur J Phys Med Rehabil. 2008;44:303-13. PMID:18762740.

14. Franchignoni F, Salaffi F. Quality of life assessment in rehabilitation medicine. Eur Med Phys. 2003;39:191-8.

15. Cieza A, Stucki G. Content comparison of health-related quality of life (HRQOL) instruments based on the international classification of functioning, disability and health (ICF). Qual Life Res. 2005;14(5):1225-37. http:// dx.doi.org/10.1007/s11136-004-4773-0

16. Teixeira-Salmela LF, Gomes-Neto M, Magalhães LC, Lima RC, Faria CDCM. Content comparisons of strokespecific quality of life based upon the international classification of functioning, disability, and health. Qual Life Res. 2009;18:765-73. PMid:19459067. http://dx.doi. org/10.1007/s11136-009-9488-9

17. Bertolucci PH, Brucki SM, Campacci SR, Juliano Y. O mini-exame do estado mental em uma população geral: impacto da escolaridade. Arq Neuropsiquiatr. 1994;52:1-7. PMid:8002795. http://dx.doi.org/10.1590/ S0004-282X1994000100001

18. Teixeira-Salmela LF, Magalhães LC, Souza AC, Lima MC, Lima RCM, Goulart F. Adaptação do Perfil de Saúde de Nottingham: um instrumento simples de avaliação da qualidade de vida. Cad Saúde Pública. 2004; 20(4):905-14. PMid:15300282. http://dx.doi.org/10.1590/ S0102-311X2004000400004

19. Cabral DL, Damascena CG, Teixeira-Salmela LF, Laurentino GEC. Confiabilidade do Perfil de Saúde de Nottingham após acidente vascular encefálico. Ciênc Saúde Coletiva. 2012;17:1313-22. http://dx.doi. org/10.1590/S1413-81232012000500025

20. Stucki G, Cieza A, Ewert T, Kostanjsek N, Chatterji S, Uestuen TB. Application of the International Classification of Functioning, Disability and Health (ICF) in clinical practice. Disabil Rehabil. 2002;24(5):281-2. PMid:12004974. http://dx.doi. org/10.1080/09638280110105222 
21. Lima RCM, Teixeira-Salmela LF, Magalhães LC, GomesNeto M. Propriedades psicométricas da versão brasileira da escala de qualidade de vida específica para acidente vascular encefálico: aplicação do modelo Rasch. Rev Bras Fisioter. 2008;12(2):149-56. http://dx.doi.org/10.1590/ S1413-35552008000200012

22. Dancey CP, Reidy J. Estatística sem matemática para psicologia: usando SPSS para Windows. Porto Alegre: Artmed; 2006.

23. Benvegnu AB, Gomes LA, Souza CT, Cuadros TBB, Pavão LW, Ávila SN. Avaliação da medida de independência funcional de indivíduos com seqüelas de acidente vascular encefálico (AVE). Rev Cienc Saúde. 2008;1(2):71-7.

24. Voos MC, Valle LER. Estudo comparativo entre a relação do hemisfério acometido no acidente vascular encefálico e a evolução funcional em indivíduos destros. Rev Bras Fisioter. 2008;12(2):113-20. http://dx.doi.org/10.1590/ S1413-35552008000200007

25. Falcoz PE, Chocron S, Mercier M, Puyraveau M, Etievent JP. Comparison of the Nottinghan Health Profile and the 36- Item Health Survey Questionnaires in the cardiac surgery. Ann Thorac Surg. 2002;37:1222-8. http://dx.doi. org/10.1016/S0003-4975(02)03371-4
26. Faria CDCM, Silva SM, Corrêa JCF, Laurentino GEC, Teixeira-Salmela LF. Identificação das categorias de participação da CIF em instrumentos de qualidade de vida Utilizados em indivíduos acometidos pelo acidente vascular encefálico. Rev Panam Salud Publica. 2012:31(4):338-44. PMid:22652975.

27. Cieza A, Geyh S, Chatterji S, Kostanjsek N, Ustün B, Stucki G. ICF linking rules: an update based on lessons learned. J Rehabil Med. 2005;37(4):212-8. PMid:16024476. http:// dx.doi.org/10.1080/16501970510040263

28. Schepers VP, Ketelaar M, Van de Port IG, Visser-Meily JM, Lindeman E. Comparing contents of functional outcome measures in stroke rehabilitation using the International Classification of Functioning, Disability and Health. Disabil Rehabil. 2007;29(3):221-30. PMid:17364773. http://dx.doi.org/10.1080/09638280600756257

\section{Correspondence}

\section{Soraia Micaela Silva}

Av. Francisco Matarazzo, 612, Barra Funda

CEP 05001-100, São Paulo, SP, Brasil

e-mail: soraia.micaela@uninove.edu.br 